\title{
Load-Unload Response Ratio and Accelerating Moment/Energy Release Critical Region Scaling and Earthquake Prediction
}

\author{
Xiang-Chu Yin, ${ }^{1,2}$ Peter Mora, ${ }^{3}$ Keyin Peng, ${ }^{1,2}$ \\ Yu CANG WANG, ${ }^{1,3}$ and DiOn WeATHERLEY ${ }^{3}$
}

\begin{abstract}
The main idea of the Load-Unload Response Ratio (LURR) is that when a system is stable, its response to loading corresponds to its response to unloading, whereas when the system is approaching an unstable state, the response to loading and unloading becomes quite different. High LURR values and observations of Accelerating Moment/Energy Release (AMR/AER) prior to large earthquakes have led different research groups to suggest intermediate-term earthquake prediction is possible and imply that the LURR and AMR/AER observations may have a similar physical origin. To study this possibility, we conducted a retrospective examination of several Australian and Chinese earthquakes with magnitudes ranging from 5.0 to 7.9, including Australia's deadly Newcastle earthquake and the devastating Tangshan earthquake. Both LURR values and best-fit power-law time-to-failure functions were computed using data within a range of distances from the epicenter. Like the best-fit powerlaw fits in AMR/AER, the LURR value was optimal using data within a certain epicentral distance implying a critical region for LURR. Furthermore, LURR critical region size scales with mainshock magnitude and is similar to the AMR/AER critical region size. These results suggest a common physical origin for both the AMR/AER and LURR observations. Further research may provide clues that yield an understanding of this mechanism and help lead to a solid foundation for intermediate-term earthquake prediction.
\end{abstract}

Key words: LURR (Load-Unload Response Ratio), AMR (Accelerating Moment Release), AER (Accelerating Energy Release), CPH (Critical Point Hypothesis), earthquake prediction, critical region scaling.

\section{Introduction}

According to the critical point hypothesis (KeILIS-BoroK, 1990; SORNETTE and Sornette, 1990; Sornette and SAmmis, 1995; Bowman et al., 1998), the earth's crust is not perpetually in a critical state. The occurrence of a large or great earthquake in a region appears to dissipate a sufficient proportion of the

\footnotetext{
${ }^{1}$ State Key Laboratory of Nonlinear Mechanics, Chinese Academy of Sciences, Beijing, 100080, China. E-mails: xycin@public.bta.net.cn; yin@lnm.imech.ac.cn

${ }^{2}$ Center for Analysis and Prediction, China Seismological Bureau, Beijing, 100036, China.

${ }^{3}$ QUAKES, Department of Earth Sciences, The University of Queensland, Brisbane, Australia. E-mails: mora@quakes.uq.edu.au; wangyc@quakes.uq.edu.au; weatherley@quakes.uq.edu.au
} 
accumulated energy to remove the crust from a critical state. Subsequently, tectonic loading drives the crust back towards the critical state. During the establishment of criticality, seismic moment release accelerates in the region surrounding the epicenter of the ensuing large or great earthquake. The Accelerating Moment/Energy Release (AMR/AER) sequences may be identified by fitting cumulative moment/energy release prior to a large or great earthquake to a power-law time-to-failure relation (Bufe and VArnes, 1993; Bowman et al., 1998; Jaumé and Sykes, 1999). Such a fit provides an intermediate-term prediction of the time of occurrence of the large or great earthquake.

It has been suggested that the acceleration in seismic moment release is due to the establishment of long-range correlations in the regional stress field. Such long-range correlations prepare the region for a large earthquake (SYKES and JAUMÉ, 1990; Rundle et al., 1999; SAmmis and Smith, 1999; Mora and Place, 2002). Once in the critical state, only a very small stress perturbation, such as that caused by the earth tides, may be sufficient to trigger earthquakes. Assuming the earth tides are sufficient to trigger earthquakes, especially moderate earthquakes, a parameter called the Load-Unload Response Ratio (LURR) may be used as a measure of the proximity to criticality (YIN and YIN, 1991; YIN, 1993; YIN et al., 1994, 1995, 2000).

From the viewpoint of Damage Mechanics, the preparation process for an earthquake is the deformation and damage process of the focal media. LURR has been proposed as a measure of this process. LURR is typically defined as the ratio of Benioff Strain release during loading cycles compared to that during unloading cycles on optimally oriented (or specified) fault planes as induced by the earth tides. High LURR values (larger than unity) indicate that a region is prepared for a large or great earthquake.

Both high LURR values and observations of Accelerating Moment/Energy Release (AMR/AER) prior to large earthquakes have led different research groups to suggest intermediate-term earthquake prediction is possible. In recent years, a relationship between the magnitude of a large or great earthquake and the size of the region where a power-law time-to-failure function best fits cumulative moment release has been noted (BOWMAN et al., 1998; JAUMÉ and SYKES, 1999). These results showed that AMR/AER exhibits a critical region size that scales with magnitude. Meanwhile, we have found that there is a correlation between LURR values and size of regions before large earthquakes. Thus, the question arises: Do AMR/AER and LURR have a common physical mechanism? In this paper, we compare the critical region magnitude scaling relations for the two phenomena aiming to answer this question.

\section{LURR as a Predictor of Large or Great Earthquakes}

In previous years, a series of successful intermediate-term predictions have been reported for strong earthquakes in China and other countries using the LURR 
parameter (YIN and YIN, 1991; YIN, 1993; YIN et al., 1994, 1995, 1996, 2000). While further research is required to analyze the null hypothesis and study the statistical likelihood of successful predictions, these results have provided encouragement that LURR anomalies may be a predictor of large or great earthquakes.

Several studies of LURR in Japan have been conducted for three regions - south Kanto region $\left(34.5^{\circ}-36^{\circ} \mathrm{N} ; 139^{\circ}-141^{\circ} \mathrm{E}\right)$, Tottori-Kobe region (circular region with center $35.3^{\circ} \mathrm{N} ; 133.7^{\circ} \mathrm{E}$ and radius $\left.300 \mathrm{~km}\right)$ and Tokai region $\left(34^{\circ}-35.5^{\circ} \mathrm{N} ; 137.5^{\circ}-\right.$ $\left.139^{\circ} \mathrm{E}\right)$. The results of LURR for these three regions are shown in Figures 1-3, respectively. For the South Kanto region, high LURR values appeared during the second half of 1999 to the beginning of 2000 and then a series strong earthquakes with magnitude larger or equal to 6 occurred in this region. It is shown in Figure 2 that before the 1995 January Kobe earthquake (M 7.2) there is a significant LURR anomaly and it lasted for more than two years. The anomaly reappeared since the second half of 1999 afterwhich the Tottori earthquake occurred (October 6th, 2000, magnitude M 7.3). The LURR plot for the Tokai region of Figure 3 shows a high LURR value in mid-1995, followed by magnitude 5-6 earthquakes 1-2 years later. In mid-1998, the plot exhibited a very sharp spike in LURR with a maximum value reaching 23. Although the null hypothesis must be evaluated, the high LURR value is significant according to an analysis given in YIN et al. (2000). Based on this spike, we are expecting that some events with magnitude about M 6 or greater may soon occur in this region, probably in 2001 or 2002, although further research is required to estimate the likelihood. These results were presented at the 2nd ACES Workshop, Oct. 15-21, 2000, Hakone, and Japan.

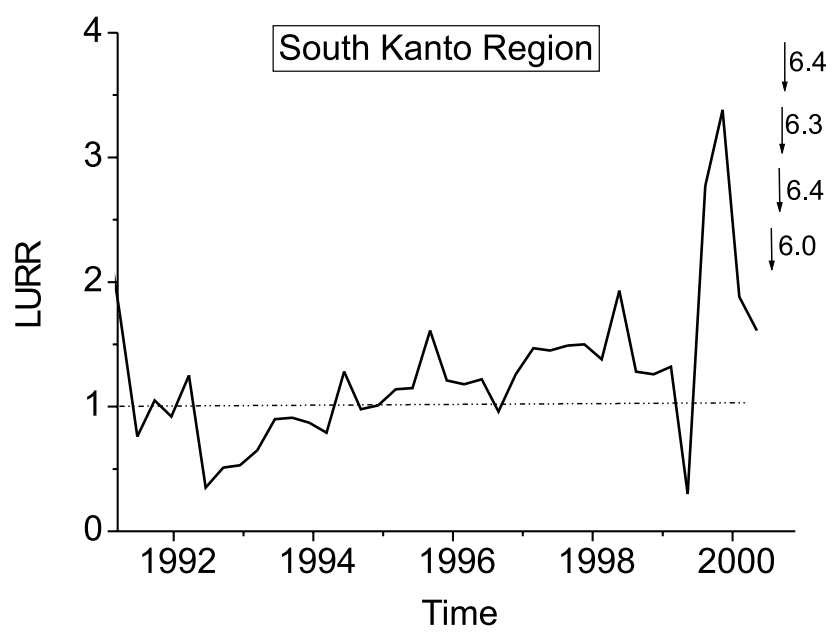

Figure 1

LURR value versus time in the south Kanto region. 


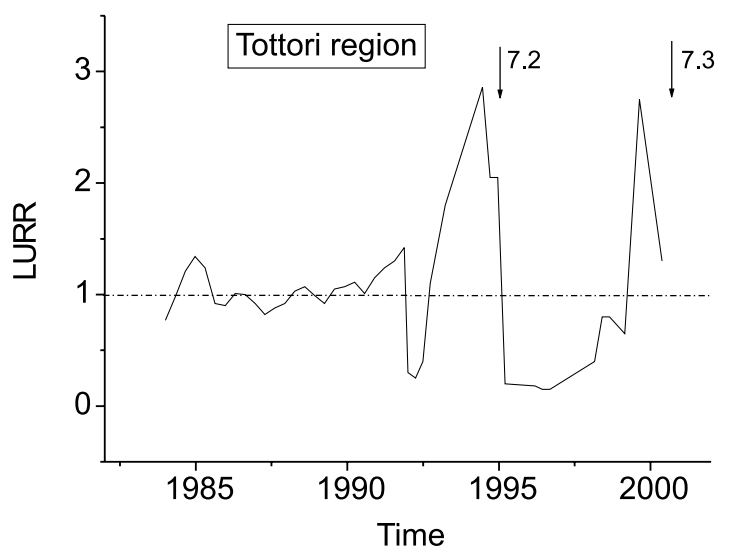

Figure 2

The LURR anomaly prior to the Kobe earthquake and the Tottori earthquake.

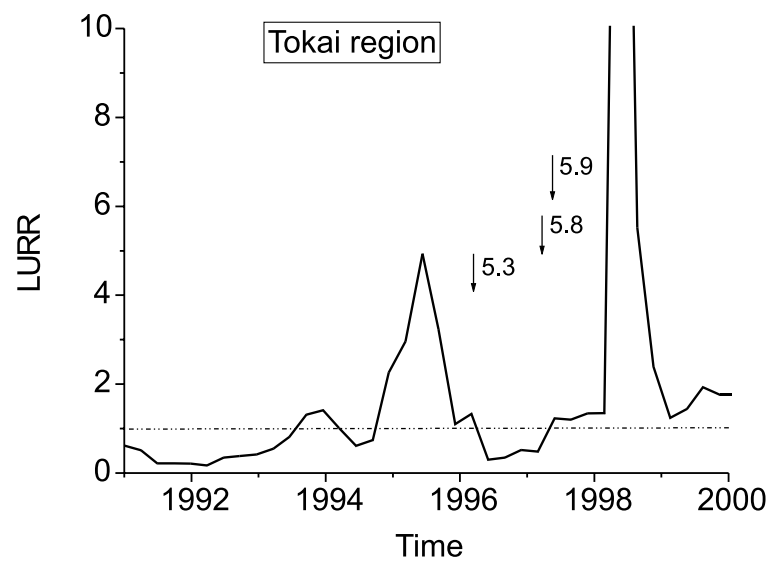

Figure 3

The variation of LURR in the Tokai region.

Recently, at the request of a seismologist from South Australia in December 2000 - David Love of the Department of Primary Industries - we analyzed the LURR and AMR within South Australia. Results at optimal radii are shown in Figures 4 and 5, respectively. These plots were transmitted to D. Love on February 8 and 9, 2000 along with additional analyses for different region sizes. According to the results, it appears that the crust of South Australia may be in a preparatory stage for a magnitude about 5.5-6 earthquake during the period 2001/3 to 2002/6 in the BurraPeterborough region within about a $150 \mathrm{~km}$ radius of Peterborough. These results will be reported in detail elsewhere. 


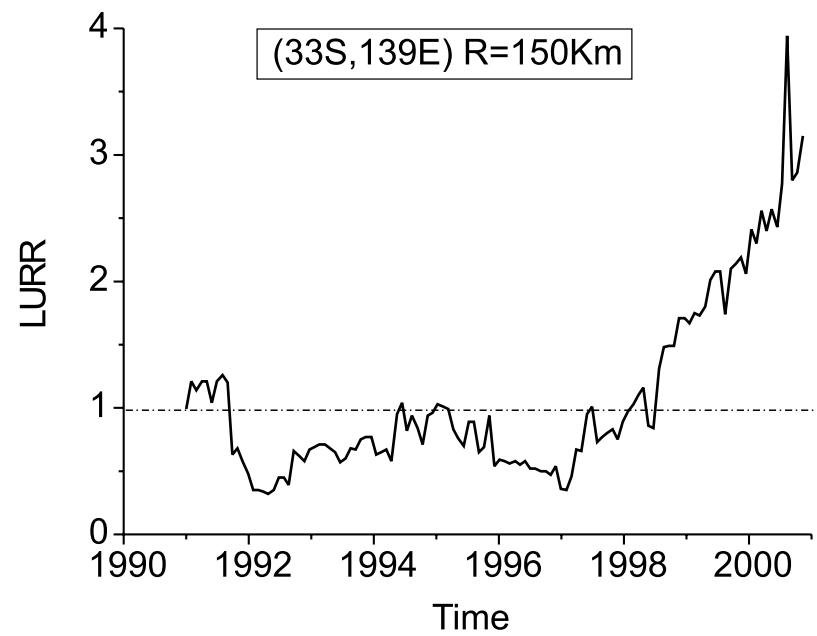

Figure 4

The variation of LURR in the Peterborough region, Australia (time window 1 year with sliding step 1 month. This plot is at the optimal radius that maximizes the peak LURR value.

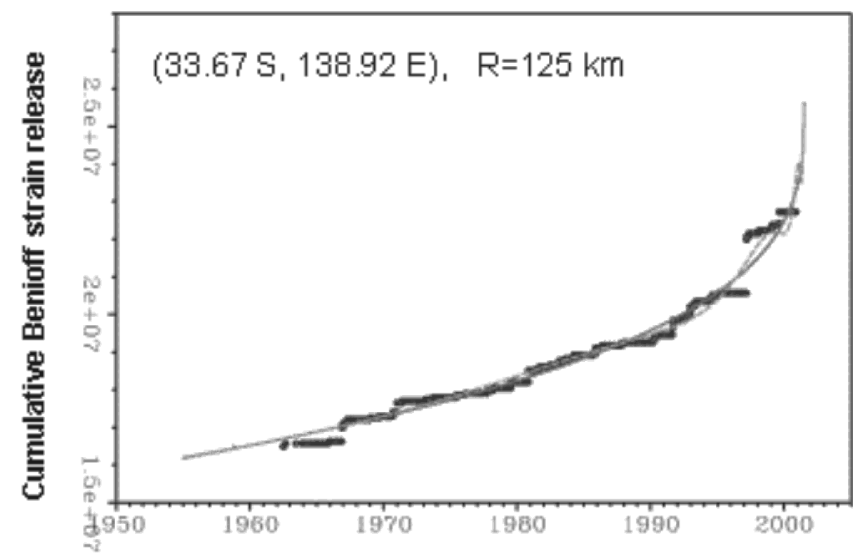

Figure 5

Power-law fits with and without log-periodic fluctuations using data from South Australia within a radius of $125 \mathrm{~km}$ around Burra (Burra is about $80 \mathrm{~km}$ south of Peterborough). This radius maximized the fit parameter $C=($ RMS error power law fit $) /($ RMS error linear fit $)$. According to the best-fit power law, the critical point time when the crust is primed for an earthquake will occur around mid-2001, and the predicted Benioff strain release at the critical point implies the expected magnitude is around 5.5. Using different radii around Burra, the predicted time fluctuates between mid-2001 and mid-2002 and magnitude fluctuated between 5.5 and 5.8 . 
In the following, we compute the LURR anomaly for different region sizes before several large events to obtain the optimal radius that maximizes LURR. This is then compared to the optimal AMR/AER region size termed the critical region size.

First we conducted a retrospective AMR examination of several Australian and Chinese earthquakes with magnitude 5-7.9, including Australia's deadly Newcastle earthquake which occurred in 1989 and the devastating Tangshan earthquake which occurred in 1976. For each event, both LURR anomalies and best-fit power-law timeto-failure functions are computed using data within a range of different radii from the epicenter (i.e., using data within different region sizes). The best-fit power-law time-tofailure functions are defined here as those that optimize the goodness of fit parameter $C=(R M S$ error power law fit $) /($ RMS error linear fit $)$. The optimal radius for AMR is defined as the radius which minimizes the fit parameter $C$. Figure 6 is a plot of the power law goodness of fit parameter $C$ as a function of region size for the sequences prior to the $1997 \mathrm{M}=5.0$ Burra earthquake, Australia, the $1989 \mathrm{M}=5.7$ Newcastle earthquake, Australia, the $1995 \mathrm{M}=6.5$ Wuding earthquake, China, the $1990 \mathrm{M}=7.0$ Gonghe earthquake, China, and the $1976 \mathrm{M}=7.9$ Tangshan earthquake, China. For small region sizes, the data shows considerable scatter. This is due to the paucity of seismic data for regions of these sizes. For the largest region sizes considered, cumulative moment release is not well represented by a power-law relation and the goodness of fit parameter becomes large. The optimal radii which specify the critical region size are $125,125,200,250$ and $650 \mathrm{~km}$, respectively. Figure 7 shows typical power-law fits for these earthquakes for the AMR/AER sequences for their optimal radii.

Subsequently the LURR values for the same five Australian and Chinese earthquakes were computed using data within several different radii from the epicenter to compute the LURR critical region size (or optimal radius for LURR) which is defined as the radius that maximizes the peak LURR value just prior to the earthquake. The time windows for all cases are one year. Figure 8 shows the relation between peak LURR values and radii. The optimal radii for LURR are 75, 100, 200, 300, $600 \mathrm{~km}$ respectively for the magnitude 5.0, 5.7, 6.5, 7.0 and 7.9 earthquakes' analyses. These results show a clear correlation between LURR critical region size and magnitude.

The plots in Figure 9, delineate the LURR values for each event, using data within the LURR critical regions (optimal radii). High LURR values occur months to years prior to each event and some intermediate-term earthquake predictions have been made including the 1995 Wuding $\mathrm{M}=6.5$ earthquake (YIN et al., 1995, 1996, 2000) and the 1990 Gonghe $M=7.0$ earthquake (unpublished report, in Chinese).

Both AMR/AER and LURR exhibit a critical region size that scales with magnitude. Figure 10 shows the critical region size for AMR/AER versus the critical region size for LURR for the five earthquakes analyzed. A strong correlation is evident between the AMR/AER and LURR critical region sizes, suggesting these two observations have a common physical mechanism. Recent simulations demon- 

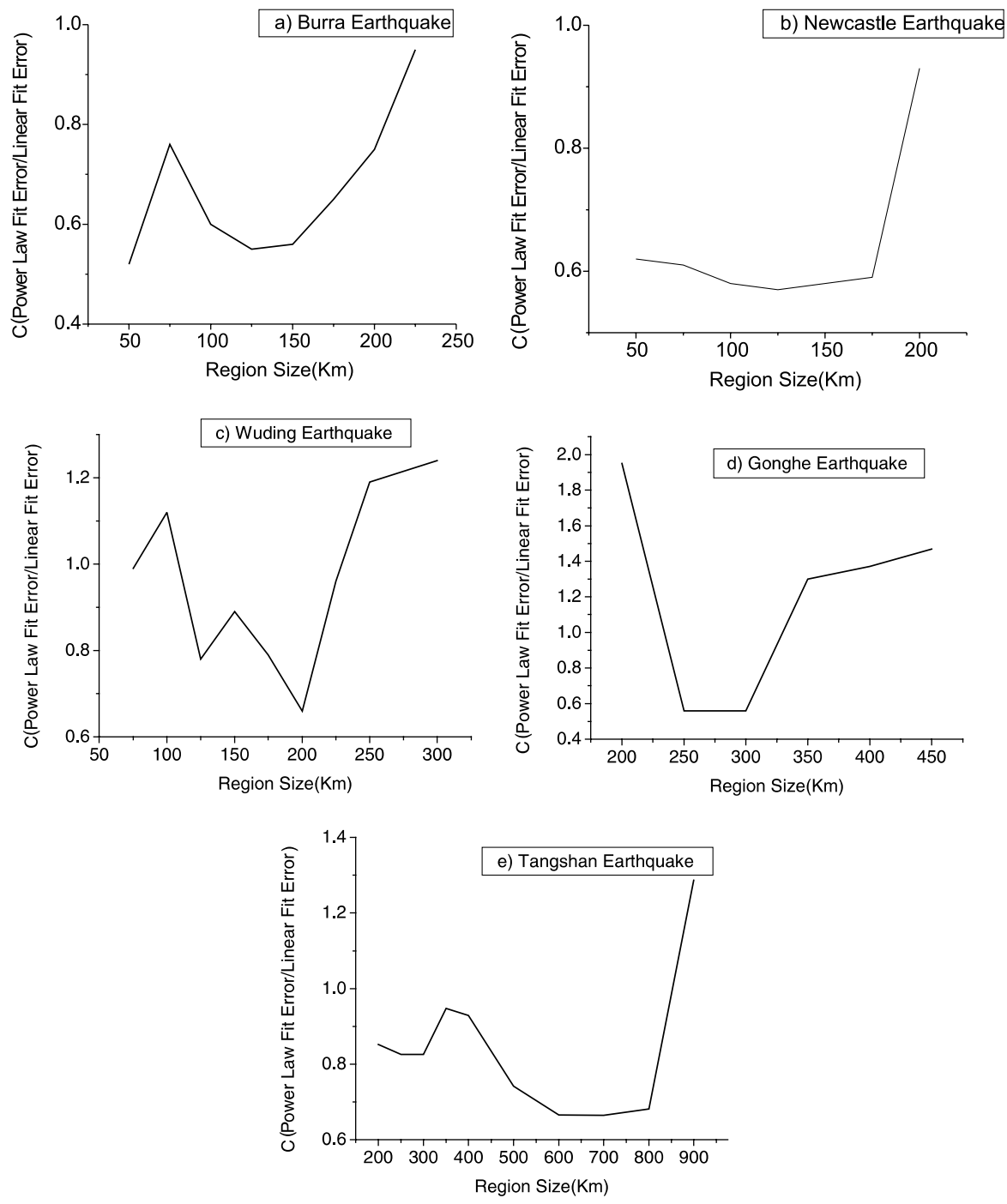

Figure 6

The goodness of power-law fit parameter $C$ as a function of region size for the AMR/AER sequences prior to (a) the $1997 \mathrm{M}=5.0$ Burra earthquake, Australia, (b) the $1989 \mathrm{M}=5.7$ Newcastle earthquake, Australia, (c) the $1995 \mathrm{M}=6.5$ Wuding earthquake, China, (d) the $1990 \mathrm{M}=7.0$ Gonghe earthquake, China, and (e) the $1976 \mathrm{M}=7.9$ Tangshan earthquake, China.

strate Accelerating Moment/Energy Release (MorA et al., 2000) and an evolution in stress correlations prior to large events (MORA and PlACE, 2002; WEATHERLEY et al., 2002) consistent with that predicted by the Critical Point Hypothesis. This suggests a mechanism that is CPH or CPH-like. If so, LURR may offer an approach to detect the critical sensitivity (WEI et al., 2000; MORA et al., 2002) of the crust as it 
a)

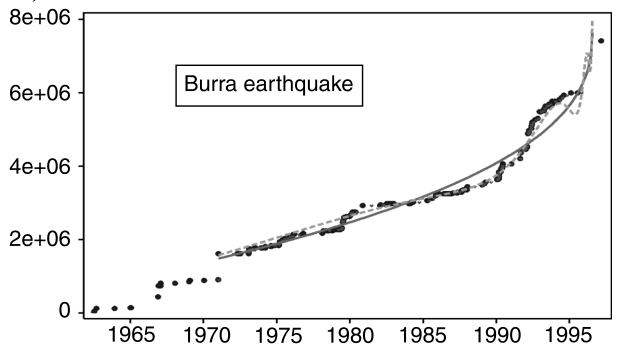

c)

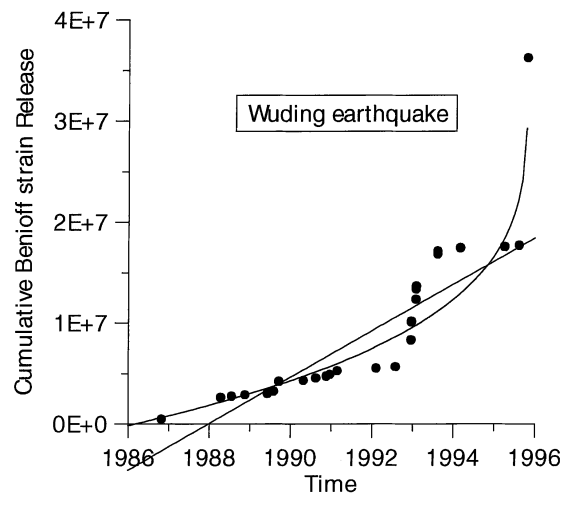

b)

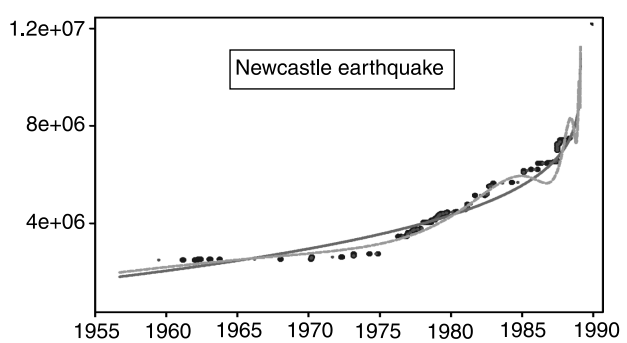

d)

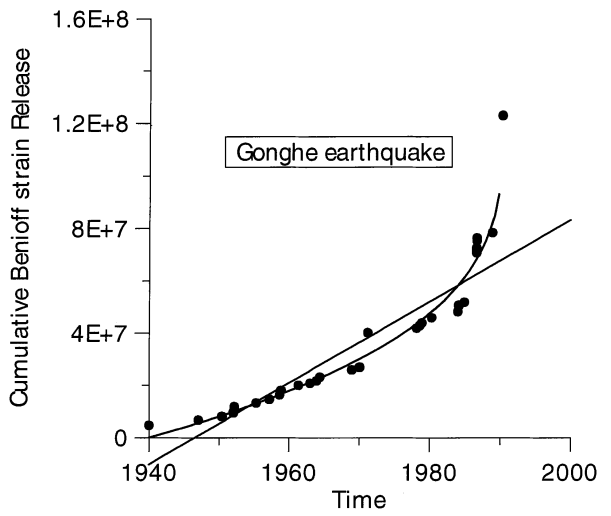

e)

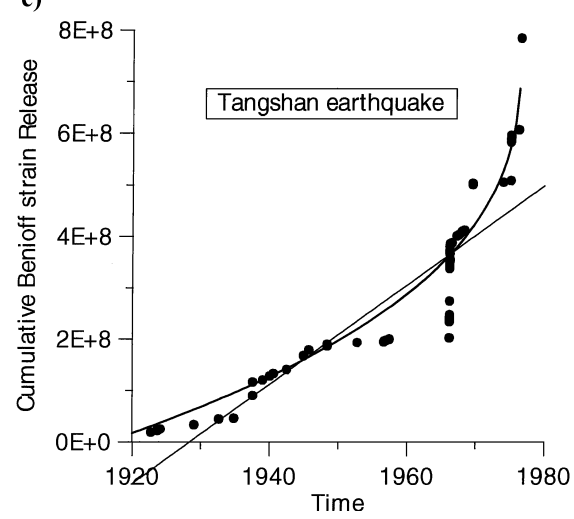

Figure 7

Typical power-law fits for these earthquakes for the radii, which minimize the fit parameter $C$ in Figure 6 . In Figures $7 \mathrm{a}$ and $7 \mathrm{~b}$, the power-law fit and power-law fit with log-periodic fluctuations are shown. In Figures $7 \mathrm{c}$ through $7 \mathrm{e}$, the power law fit and linear fit are shown.

approaches a critical point in the lead-up to a large event. Furthermore, based on the results presented in Figure 10, the critical region size - magnitude scaling relation for AMR/AER and/or LURR provides a means to estimate the magnitude of an oncoming earthquake. 

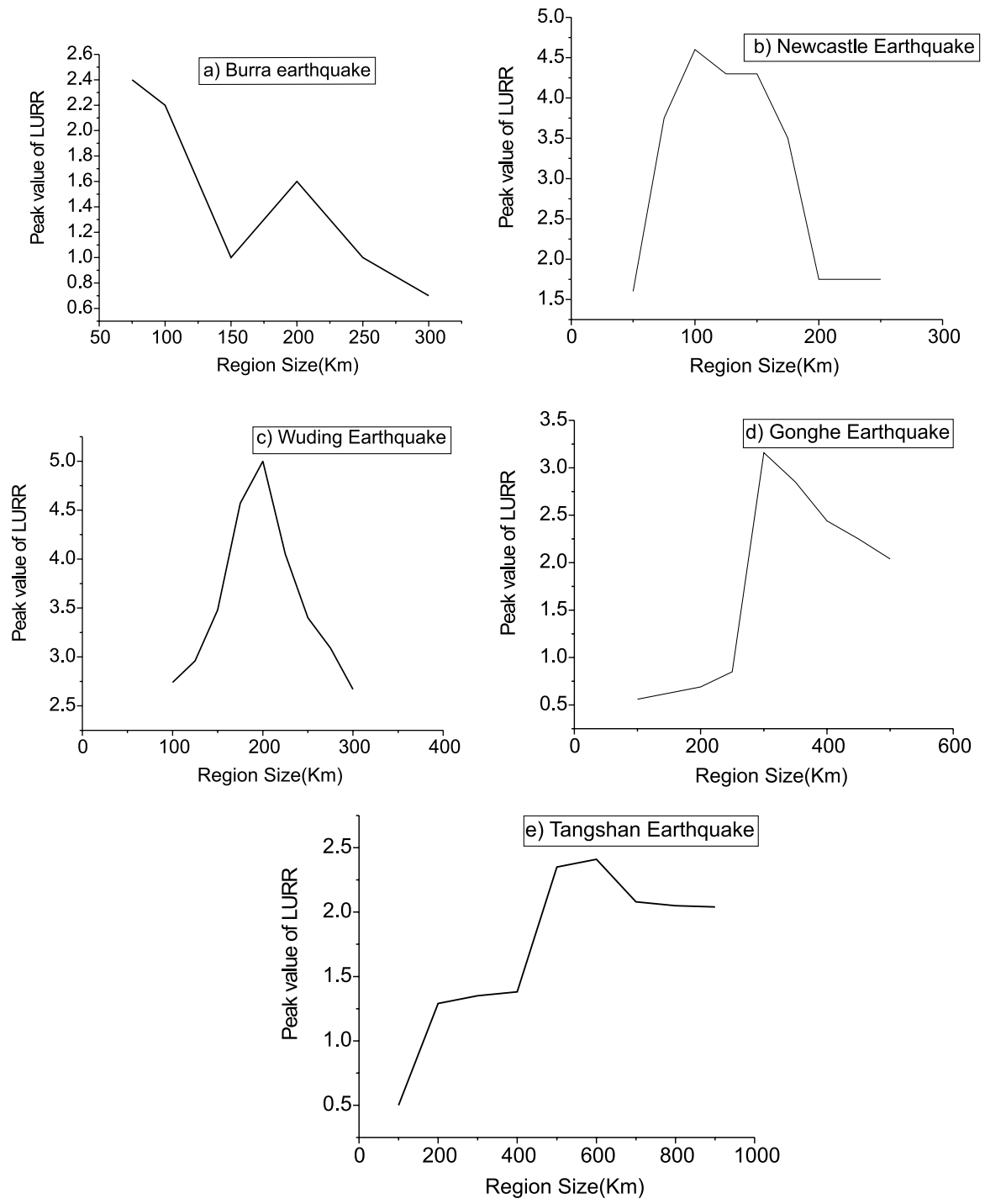

Figure 8

Peak LURR value versus region size for (a) the $1997 \mathrm{M}=5.0$ Burra earthquake, Australia, (b) the 1989 $\mathrm{M}=5.7$ Newcastle earthquake, Australia, (c) $1995 \mathrm{M}=6.5$ earthquake, China, (d) the $1990 \mathrm{M}=7.0$ Gonghe earthquake, China, and (e) the $1976 \mathrm{M}=7.9$ Tangshan earthquake, China.

\section{Discussion and Conclusions}

According to the critical point hypothesis $(\mathrm{CPH})$, the occurrence of a large or great earthquake in a region removes the crust from a critical state. Tectonic loading 

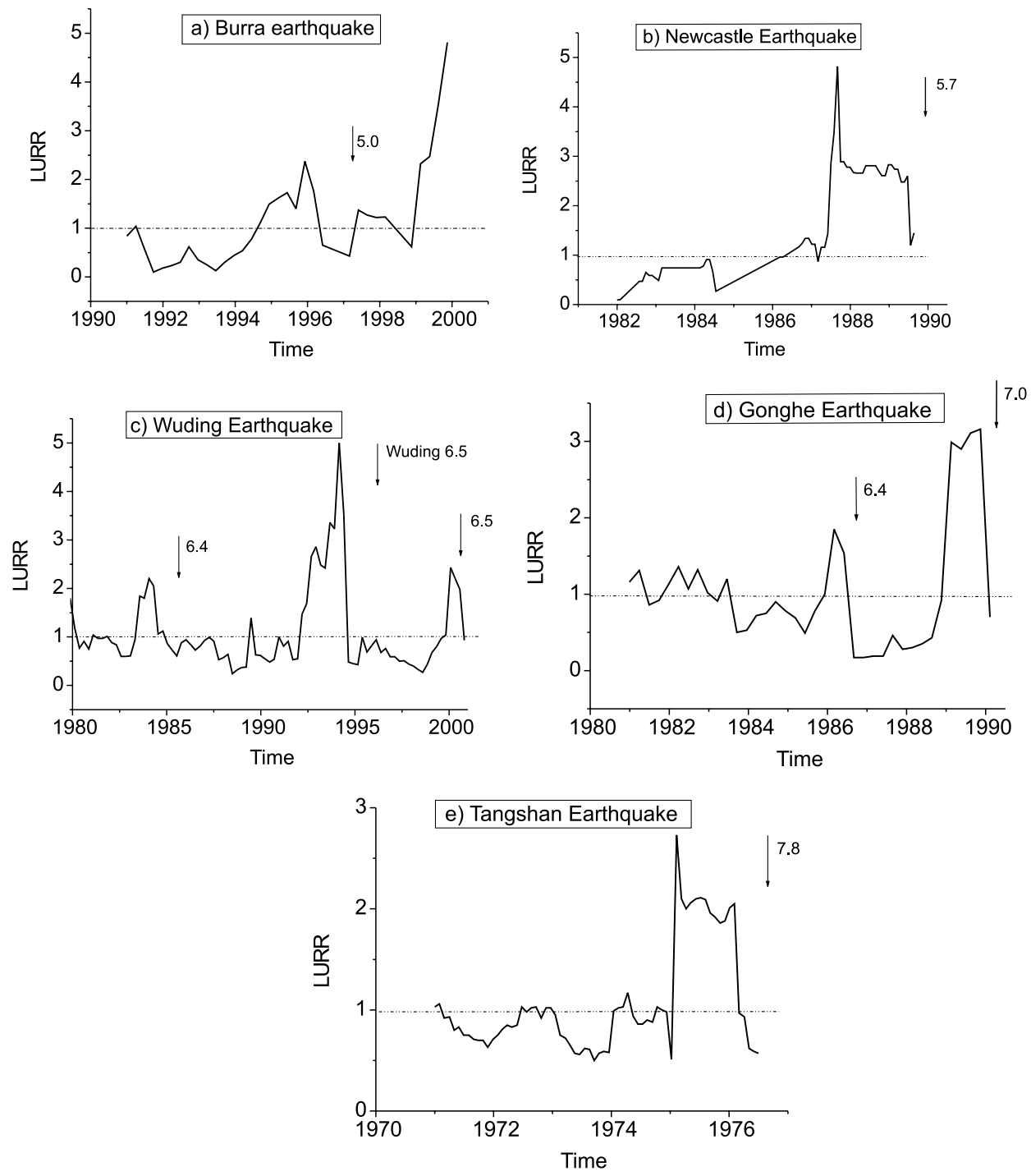

Figure 9

LURR value as a function of time for the five regions using data within the LURR critical region size (optimal radii that maximize peak LURR value) as determined by Figure 8 . Namely, using region sizes of $75,100,200,300$ and $600 \mathrm{~km}$ for plots (a) through (e) respectively. The time windows for 5 events are 1 year.

drives the crust back towards the critical state. During the establishment of criticality, some phenomena appear including:

- Accelerating seismic activity of moderate-sized earthquakes (Ellsworth et al., 1981; Keilis-Borok, 1990; Sornette and Sornette, 1990; Sornette and SAMmis, 1995; KNOPOFF et al., 1996 and Bowman et al., 1998). 


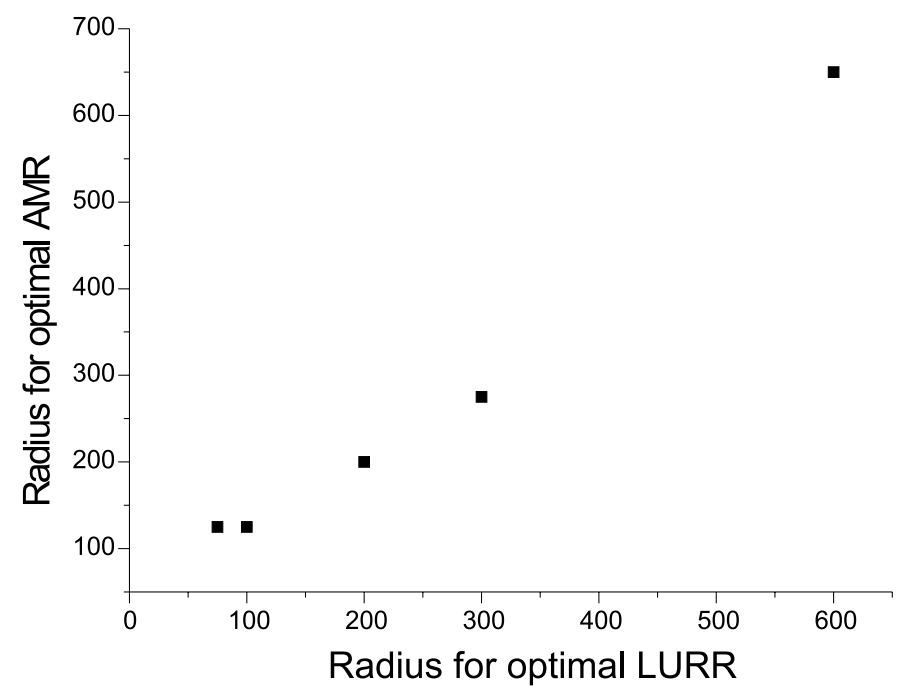

Figure 10

The critical region size for AMR/AER versus the critical region size for LURR for the five earthquakes analyzed.

- Accelerating seismic moment release (time-to-failure power law) AMR/AER (BUFE and Varnes, 1993; Bowman et al., 1998; Jaumé and Sykes, 1999).

- Establishment of long-range correlations in the regional stress field (SYKeS and Jaumé, 1990; Rundle et al., 1999; Sammis and Smith, 1999; Mora and Place, 2002).

- Critical sensitivity (WeI et al., 2000).

- Triggering earthquakes significantly by tidal stress (GRASSO and SoRNETTE, 1998).

- Anomalous LURR (high value) (YIN and YIN, 1991; YIN, 1993; YIN et al., 1994, 1995, 2000).

On the other hand, from the view point of meso-mechanics (KRAJCINOviC, 1996; KUKSHENKO et al., 1996), when a system - say, a specimen of heterogeneous media is approaching the critical point (fracture), the micro-cracks grow in both number and size so that the interaction between them becomes increasingly intense, and consequently the system will become considerably more sensitive. That means a tiny external disturbance acting on it should induce a significant response. Now it is easy to understand the above-mentioned phenomena and they could be divided into two groups: The first group (first 3 phenomena) is due to the appearance of bigger cracks (moderate-sized events). The second group (last 3 ) is concerned with sensitivity and it is the consequence of the first phenomena (i.e., the increase in sensitivity occurs when crack interactions become stronger). In summation, all of the above-mentioned phenomena may have the same underlying physical mechanism under the framework of the critical point model. 
The results presented here are preliminary since only five earthquakes spanning 2.9 magnitudes units have been analyzed. All five earthquakes exhibit both AMR/ AER and high LURR values near the end of the AMR/AER sequence. The results establish that both AMR/AER and LURR have a similar critical region size that this critical region size scales with mainshock magnitude. This suggests that both the AMR/AER and LURR observations have a common physical origin and that the mechanism is $\mathrm{CPH}$ or CPH-like. Further work may provide clues that yield an understanding of the mechanism underlying AMR/AER and LURR, and will potentially lead to a solid foundation for intermediate-term earthquake prediction.

\section{Acknowledgments}

The authors wish to thank Dr. KOHJI HOSONO, Meteorological Research Institute of the Japan Meteorological Agency for supplying seismic data from Japan. We would also like to thank the Australian Geological Survey Organization and KEVIN Mccue for provision of the Australian Earthquake Catalog, Russell Cuthbertson for assistance in data provision and formatting and DAVID LOVE of Primary Industries and Resources of South Australia for provision of the South Australian catalog. This research is supported by the Natural Sciences Foundation of China (Grant No. 19732060 and 40004002), the State Key Laboratory of Nonlinear Mechanics of the Chinese Academy of Sciences, the Center for Analysis and Prediction of the Chinese Seismological Bureau, the ARC IREX ACES International Visitors Program, the University of Queensland, and the Australian Research Council.

\section{REFERENCES}

Bowman, D. D., Oulllon, G., Sammis, C. G., Sornette, A., and Sornette, D. (1998), An Observational Test of the Critical Earthquake Concept, J. Geophys. Res. 103, 24,359-24,372.

Bufe, C. G. and Varnes, D. J. (1993), Predictive Modeling of the Seismic Cycle of the Greater San Francisco Bay Region, J. Geophys. Res. 98, No. B6, pp. 9871-9883.

Ellsworth, W. L., Lindh, A. G., Prescott, W. H., and Head, D. G., The 1906 San Francisco earthquake and the seismic cycle. In Earthquake Prediction: An International Review, eds. Simpson, D. W., and Richards, P. G. (AGU, Washington, D. C. 1981) pp. 21-27.

Grasso, J. and Sornette, D. (1998), Testing Self-organized Criticality by Induced Seismicity, J. Geophys. Res. 103, B12, 29,965-29,987.

Jaumé, S. C. and Sykes, L. R. (1999), Evolving Towards a Critical Point: A Review of Accelerating Seismic Moment/Energy Release Prior to Large and Great Earthquakes, Pure Appl. Geophys. 155, 279-306.

KeIlis-BoroK, V. (1990), The Lithosphere of the earth as a large nonlinear system. In Quo Vadimus: Geophysics for the Next Generation, Geophys. Monogr. ser. vol. 60 (ed. G. D. Garland and J. R. Apel), pp. 81-84, AGU, Washington, D. C.

Knopoff, L., Levshina, T., Keilis-Borok, V. I., and Mattoni, C. (1996), Increased Long-range Intermediate-magnitude Earthquake Activity prior to Strong Earthquakes in California, J. Geophys. Res. 101, 5779-5796.

Krajcinivic, D. Damage Mechanics, (Elsevier, New York, 1996). 
Kukshenko, V., Tomlin, N., Damaskinskaya, E., and Lockner, D. (1996), A Two-stage Model of Fracture of Rocks, Pure Appl. Geophys. 146, 353-264.

Mora, P., Place, D., Abe, S., and Jaumé, S. (2000), Lattice solid simulation of the physics of fault zones and earthquakes: The model, results and directions. In Geocomplexity and the Physics of Earthquakes (eds. Rundle, J.B., Turcotte, D.L. and Klein, W.), pp. 105-125 (AGU, Washington).

Mora, P., Wang, Y. C., Yin, C., Place, D., and Yin, X. C. (2002), Simulation of the Load-Unload Response Ratio and Critical Sensitivity in the Lattice Solid Model, Pure Appl. Geophys. 159, 2525-2536.

Mora, P. and Place, D. (2002), Stress Correlation Function Evolution in Lattice Solid Elasto-dynamic Models of Shear and Fracture Zones and Earthquake Prediction, Pure Appl. Geophys. 159, 2413-2427.

Rundle, J. B., Klein, W., and Gross, S. (1999), A Physical Basis for Statistical Patterns in Complex Earthquake Populations: Models, Predictions and Tests, Pure Appl. Geophys. 155, 575-607.

Sammis, C. G. and Smith, S. W. (1999), Seismic Cycles and the Evolution of Stress Correlation in Cellular Automation Models of Finite Fault Networks, Pure Appl. Geophys. 155, 307-334.

Sornette, A. and Sornette, D. (1990), Earthquake Rupture as a Critical Point: Consequences for Telluric Precursors, Tectonophysics 179, 327-334.

Sornette, D. and Sammis, C. G. (1995), Complex Critical Exponents from Renormalization Group Theory of Earthquake Prediction, J. Phys. I. France 5, 607-619.

Sykes, L. R. and Jaumé, S. (1990), Seismic Activity on Neighboring Faults as a Long-term Precursor to Large Earthquakes in the San Francisco Bay Area, Nature 348, 595-599.

Weatherley, D., Mora, P., and XIA, M. (2002), Long-range Automaton Models of Earthquakes: Powerlaw Accelerations, Correlation Evolution, and Mode Switching, Pure Appl. Geophys. this issue.

WeI, Y. J., XIA, M. F., KE, F. J., YIN, X. C., and BAI, Y. L. (2000), Evolution Induced Catastrophe and its Predictability, Pure Appl. Geophys. 157, 1945-1957.

YIN, X. C. and YIN, C. (1991), The Precursor of Instability for Nonlinear Systems and its Application to Earthquake Prediction, Science in China 34, 977-986.

YIn, X. C. (1993), New Approach to Earthquake Prediction, PRERODA (Russia’s “Nature”), 1, pp. 21-27 (in Russian).

YIN, X. C., YIN, C., and Chen, X. Z. (1994), The Precursor of Instability for Nonlinear Systems and its Application to Earthquake Prediction - the Load-Unload Response Ratio Theory, Nonlinear Dynamics and Predictability of Geophysical Phenomena, AGU Geophysical Monograph 83 (eds. Newman, W. I., Gabrelov, A. M., and Turcotte, D.L.), pp. 55-60.

Yin, X. C., Chen, X. Z., Song, Z. P., and Yin, C. (1995), A New Approach to Earthquake Prediction - The Load-Unload Response Ratio (LURR) Theory, Pure Appl. Geophys. 145, (3/4), 701-715.

Yin, X. C., Chen, X. Z., Song, Z. P., and Wang, Y.C. (1996), The Temporal Variation in LURR in Kanto and other Regions in Japan and its Application to Earthquake Prediction, Earthquake Research in China 10, 381-385.

Yin, X. C., Wang, Y. C., Peng, K. Y., Bai, Y. L., Wang, H., and Yin, X. F. (2000), Development of a New Approach to Earthquake Prediction: Load/Unload Response Ratio (LURR) Theory, Pure Appl. Geophys. 157, 1923-1941.

Yin, X. C., Wang, Y. C., Peng, K. Y., Zhang, Y. X., and XiA, M. F. (2000), New Developments of LURR Theory and its New Application, International Workshop on Solid Earth Simulation and ACES WG Meeting, Abstract vol. (University of Tokyo, Jan 17-21, 2000).

(Received February 20, 2001, revised June 11, 2001, accepted June 25, 2001)

(12) To access this journal online:
http://www.birkhauser.ch

